\title{
ANTIOCHOS'S HIEROTHESION AT NEMRUD DAG REVISITED: ADJUSTING THE DATE IN THE LIGHT OF ASTRONOMICAL EVIDENCE
}

\author{
JUAN ANTONIO BELMONTE and A. CÉSAR GONZÁLEZ GARCÍA, \\ Instituto de Astrofísica de Canarias and Universidad de La Laguna
}

The world heritage site of the hierothesion of Antiochos I, King of Commagene, at Mount Nemrud (Turkey) certainly constitutes one of the most fascinating historical enigmas in human culture. The monument includes the famous lion "horoscope" which has often been used in various attempts to interpret and date the ruins, with controversial results. After performing on-site observations, during the summer solstice of 2009, we propose that Antiochos's monument reflects the situation of the skies at special moments of the year 49 B.C., when possibly construction of the monument would have been begun. This alternative, more substantiated than the traditional explanation, is formulated in the present paper by considering not only the lion slab but also the orientation of the eastern and western terraces of the hierothesion, and the inscriptions on the monument.

The small Kingdom of Commagene nestled between the upper course of the river Euphrates and the mountains of Anti-Taurus in the south-east of Anatolia. Despite its tiny size, Commagene played a significant role in the history of the Middle East during the late Hellenistic and early Roman periods, as a buffer state between the powerful Seleucid (later Roman) and Parthian Empires. The dynasty of Commagene was founded by King Ptolemaios (c. 163 B.C.), a member of the Orontid family of Armenian satraps and kings with Persian roots, and ended when Antiochos IV Epiphanes was deposed by Emperor Vespasian in 72 A.D. ${ }^{1}$

Antiochos I Theos (c. 69-36 B.C.) was arguably the most important of its kings, ruling for more than 30 years in one of the most challenging periods in the history of the region. He was contemporaneous with Triganes the Great of Armenia, Mithradates II and Orodes II of Parthia, the last petty Seleucid kings, Herod the Great, and Lucullus, Pompey, Crassus, Caesar and Antonius from the Roman side. Antiochos was the son of Mithradates I Kallinikos, an Orontid, and of Laodice Thea Philadelphos, daughter of the last Seleucid king of any importance, Antiochos VIII Grypus. Consequently, Antiochos was able to claim both an Iranian and a Hellenistic ancestry, which was reflected in his political behaviour, always balanced between East and West, and, most importantly, in the new cult he was going to establish in his kingdom. ${ }^{2}$

The most outstanding example of this new cult was Antiochos's burial monument on the summit of the highest peak of Commagene, Nemrud Dag (see Figure 1) at a height of $2150 \mathrm{~m}$. Earlier local inscriptions in Luwian speak about Kings Suppiluliuma and Hattusili (c. 800 B.C.), lords of Kummaha (Assyrian Kummuh, undoubtedly the original name of Commagene), who rendered worship to a sacred mountain named Hurtula, ${ }^{3}$ possibly Nemrud Dag. Mountain cult was very frequent 


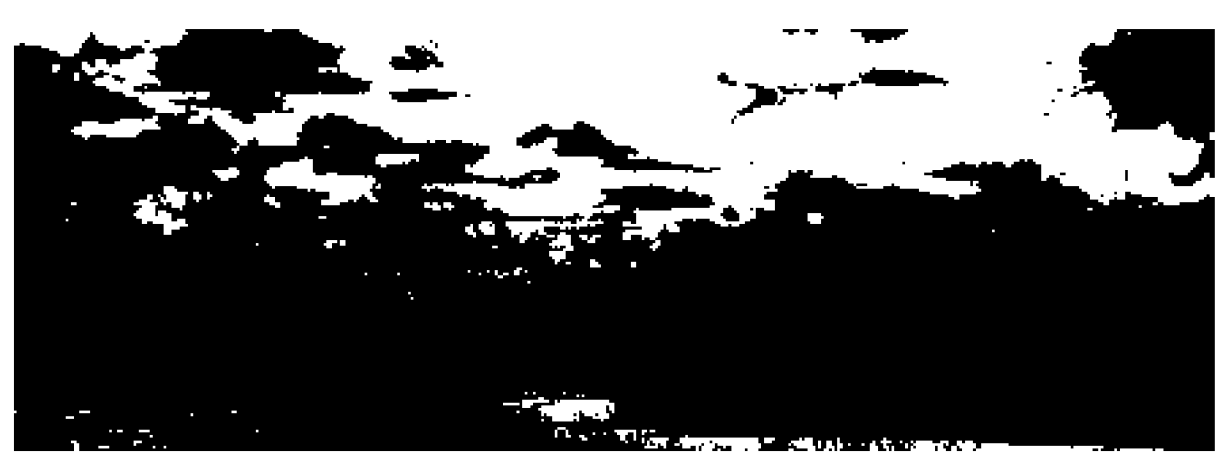

FIG.1. The Nemrud Dag range as seen from the Karakush monument across the fertile valleys of Commagene. The peak itself is indicated by an arrow mark. Nemrud Dag dominates the landscapes for dozens of kilometres. Photograph by A. C. González García.

among Late Bronze Age Hittites and their Iron Age Syrian descendents. ${ }^{4}$ Consequently, this peak already had a long history of sacredness when it was selected by Antiochos as the site of his hierothesion, as the monument is always referred in the associated inscriptions or nomos.

\section{The State of the Question}

As seen in Figure 2, the hierothesion basically consisted of a huge tumulus, still standing to a height of 50 metres, which would have covered the burial chamber (not yet found), and three terraces, eastern, western and northern (see Figure 3). The northern terrace was possibly a transitional element and was never completed. However, the eastern and western terraces included an astonishing group of five limestone cyclopean statues, nearly identical in both terraces, representing the composite images of the divinities of Antiochos's new cult, escorted by a lion and an eagle on both sides.

These were complemented on both terraces by a group of sandstone slabs representing hand-shaking (dexiosis) scenes of the king with the different deities and the well-known lion "horoscope". Unfortunately, the scenes of the eastern terraces are almost completely destroyed, but those of the western terrace have survived to our own time in an acceptable state of preservation (see Figure 4). The monument was completed by two series of portraits of Antiochos's Iranian and Hellenic ancestors represented in a pair of walls with appropriate sockets (see Figure 3); once more the surviving slabs of the western terrace are the better preserved. Apparently, these series were incomplete at the moment of Antiochos's death, and the monument was left unfinished. ${ }^{5}$ An altar was added to the eastern terrace, suggesting that an important part of the ritual may have taken place there.

On the back of the seats of the statues, Antiochos ordered the inscription of a long text, or nomos, in Greek. This includes historical and legal aspects regarding the hierothesion and the establishment of the new cult. Thanks to the inscription, we know that the hierothesion was established when Antiochos had already enjoyed "a 

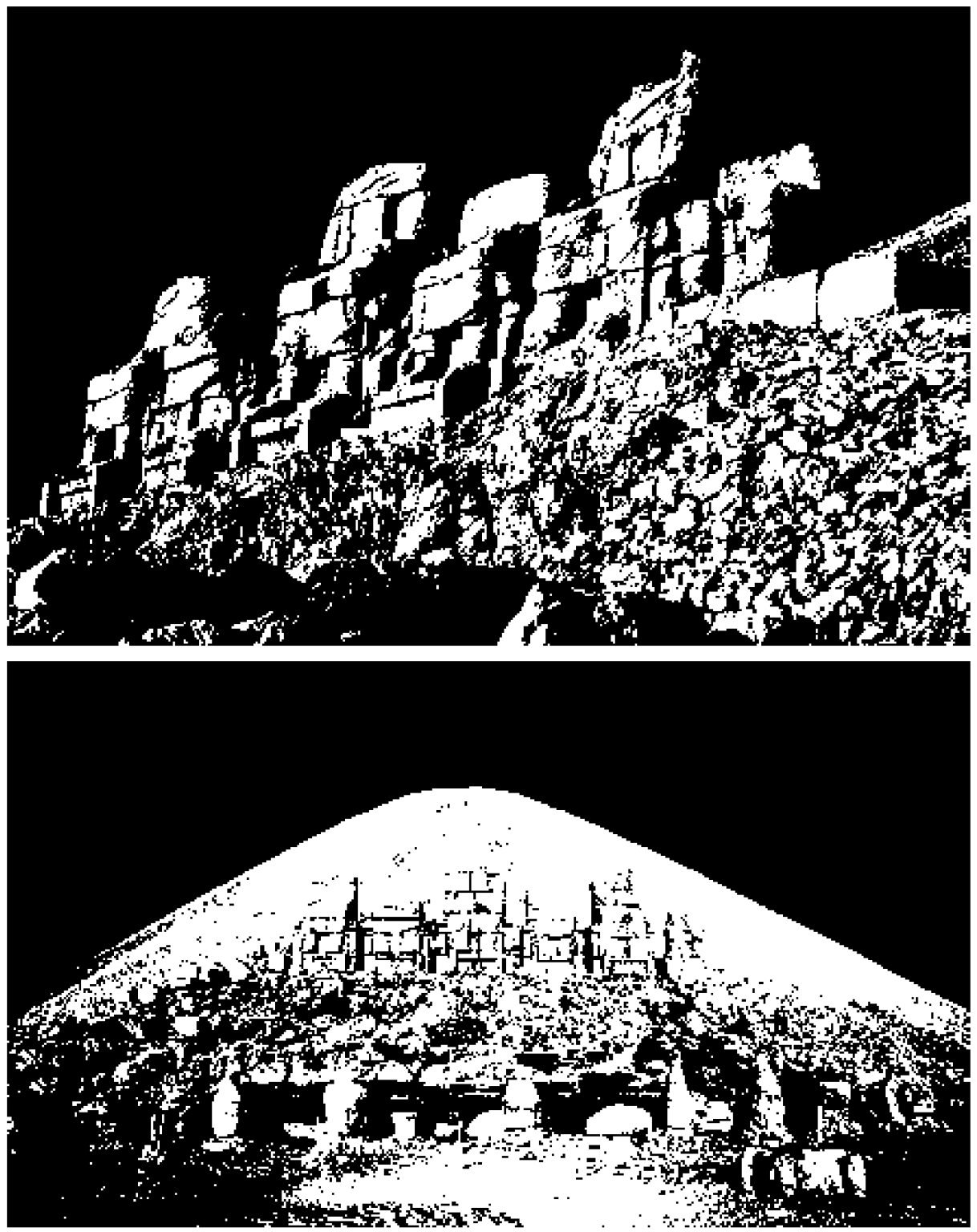

FIG. 2. The better preserved statues of the colossi at the eastern terrace of Nemrud Dag (top) and the tumulus in the background (bottom). From left (south) to right: Antiochos I, the goddess Commagene, Zeus-Orosmasdes, Apollo-Mithras-Helios-Hermes, and Artagnes-Heracles-Ares. Two eagle and lion pairs framed the statues on both left and right. These statues were perhaps facing the rising of the star Regulus (a celestial manifestation of the king himself) in the epoch of the construction of the monument. However, this was also the direction of sunrise on Loios 11 in the year 49 B.C. (see Fig. 8). Each year, Antiochos commended the celebration of a festival at his hierothesion on Loios 10 and 11, commemorating his ascent to the throne which was probably on Loios 10 in 69 B.C. Photographs by M. Sanz de Lara and J. A. Belmonte. 

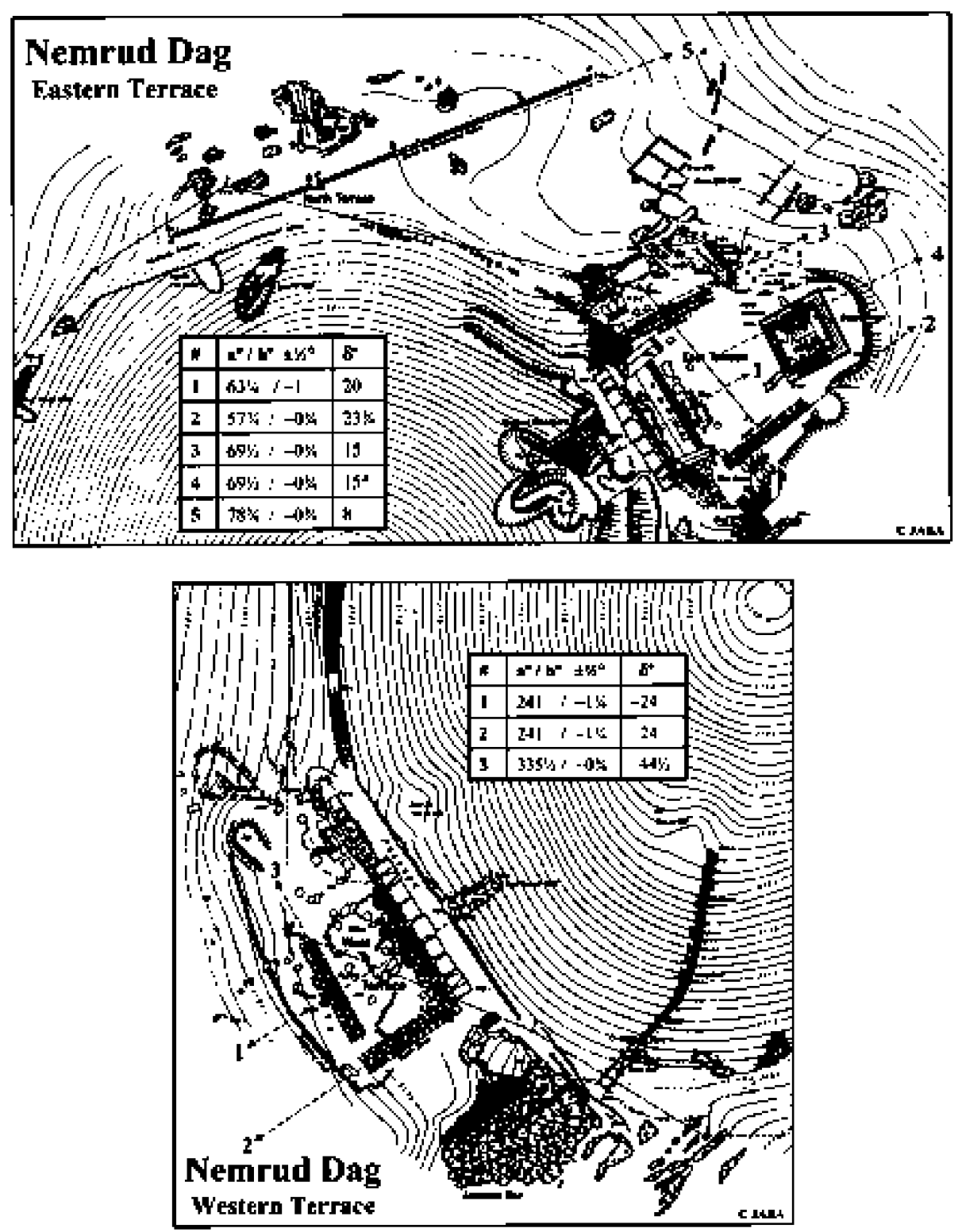

FIG. 3. Schematic diagrams and orienting data (azimuth, angular height and declination) of the most important directions at the eastern (including northern) and western terraces of Antiochos's monument at Nemrud Dag: colossi (1), southern sockets (2), northern (eastern terrace) and western sockets (3), and the long unfinished sockets and wall of the northern terrace (5), respectively. Notice the suggestive astronomical pattern included in the design of the two terraces, as discussed in Figs 2, 6 and 7. The orientation of the extensively reconstructed altar (4) is considered an average of various possible measurements. Adapted from a plan of the site by the American School of Oriental Research (1956). See the text for further discussion. 


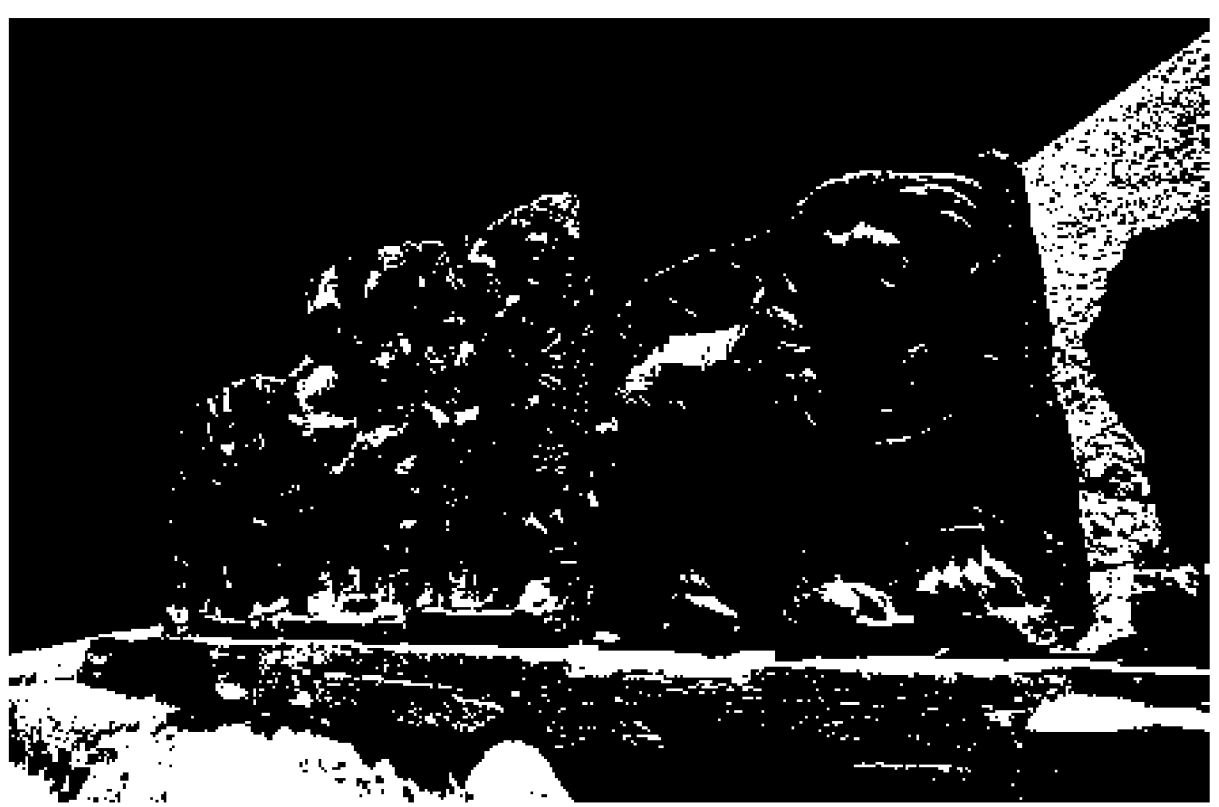

FIG. 4. Image of the relatively well-preserved frieze of sandstone slabs at the western terrace of the hierothesion (a similar one at the eastern terrace is completely destroyed), including the most famous lion "horoscope" slab (with a representation of Mars, Mercury and Jupiter - mentioned in that order - and the crescent moon) and the four dexiosis (hand-shaking) scenes of King Antiochos with Heracles, Zeus-Orosmasdes, Mithras, and Commagene, standing for the four divinities represented in the colossi. Photograph courtesy of A. Dyer and E. F. Milone. See the text for further discussion.

life of many years ... filled out in blessed fashion", and that he had escaped great dangers during his tumultuous reign, including at least two sieges of Samosat, his own capital. Most important, however, the nomos teaches us about the foundation of the new cult to be celebrated throughout the kingdom but especially at Mount Nemrud. There we read:

also new festivals for the worship of the gods and our honours will be celebrated [by] all the inhabitants of my kingdom. For my body's birthday, Audnayos the 16th, and for my coronation, Loios the 10th, these days have I dedicated to the great daimones' manifestations who guided me during my fortunate reign.... I have additionally consecrated two days annually for each festival. ${ }^{6}$

These daimones were the divinities represented in the cyclopean statues, including, from left to right (see Figure 2), a portrait of Antiochos himself, accompanied by the all-sustaining goddess Commagene, Zeus-Orosmasdes, Apollo-Mithras-HeliosHermes, and Artagnes-Heracles-Ares. Three of these gods were obvious composites of Iranian/Zoroastrian divinities (Orosmasdes, i.e. Ahura Mazda; Mithras; and Artagnes, i.e. Bahram) and Hellenistic divinities. Ahura Mazda is the Iranian interpretation of 
the Storm God (Hurrian Teshup) of ancient Kummuha, Zeus being the Hellenistic interpretation of the same god (Jupiter Dolichenus in the Roman period). Besides, both Ares and Heracles are frequently identified with the war god-hero of the Iranian people, Bahram. However, Mithras is more problematic and specialists are not fully agreed on why the Iranian god of light (and the Sun) was simultaneously identified with Helios and Hermes. ${ }^{7}$ Finally, the goddess Commagene, representing the fertility of Antiochos's land, is the most difficult to interpret correctly. Sometimes erroneously identified with Hellenistic Tyche, we strongly support the idea that she should be identified with a form of the Dea Syria, Atargatis, converted into Juno Dolichena under Roman influence, and much closer to the Iranian goddess of fertility Anahita. ${ }^{8}$ This particular case will be most relevant for our new hypothesis.

The dexiosis scenes (see Figure 4), including the fragments delivered by the excavations, show Antiochos shaking hands with the same four divinities. Heracles is dressed in his Hellenic attire, Mithras has a radiant aura, and Commagene is holding a cornucopia denoting her fertility aspect. However, ever since the earliest archaeological studies in Nemrud Dag, the lion slab has drawn most of the specialist attention. The possibility that the scene depicts a real or schematic astronomical scene or an astrological image (a sort of horoscope) introduced the possibility of dating the monument and interpreting its nature. On the slab, a lion with stars on his body, probably the constellation Leo, is represented together with a crescent moon on his chest. Three stars above the back of the lion are identified in Greek as Pyroeis of Heracles, Stilbon of Apollon, and Phaeton of Zeus (see Figure 4), standing for the planets Mars, Mercury and Jupiter, respectively.

Neugebauer and Van Hoessen argued that the scene might represent a sort of horoscope for the date 7(6) July 62 в.C. (see Figure 5, panel (b)) at the beginning of the reign of Antiochos I. ${ }^{9}$ Other dates, such as 15 July 109 B.C. (see Figure 5(a)) arguably earlier than Antiochos's ascent to the throne but perhaps related to important dynastic events - have also been maintained. ${ }^{10}$ Other speculative proposals have been discarded as unrealistic. ${ }^{11}$ Interestingly, the dexiosis scenes associated with the lion slab have been interpreted as successive conjunctions of the planets Mars, Jupiter, Mercury and the moon (supposedly standing for goddess Commagene, but proposed as such without further historical or religious analysis) with the star Regulus in the constellation Leo, as standing for King Antiochos himself. This last interpretation seems plausible. However, every attempt to relate the two previous dates to Audnayios 16 and Loios 10, the most relevant yearly dates as established in the nomos inscription, within the period of Antiochos's reign, have failed.

\section{The New Data}

In June 2009, within the context of a dedicated archaeoastronomical mission in eastern Anatolia, we visited Mount Nemrud at the precise epoch of the summer solstice (see Figure 6) in an attempt to check possible astronomical alignments and to obtain direct observations that would permit the immediate correction of the 


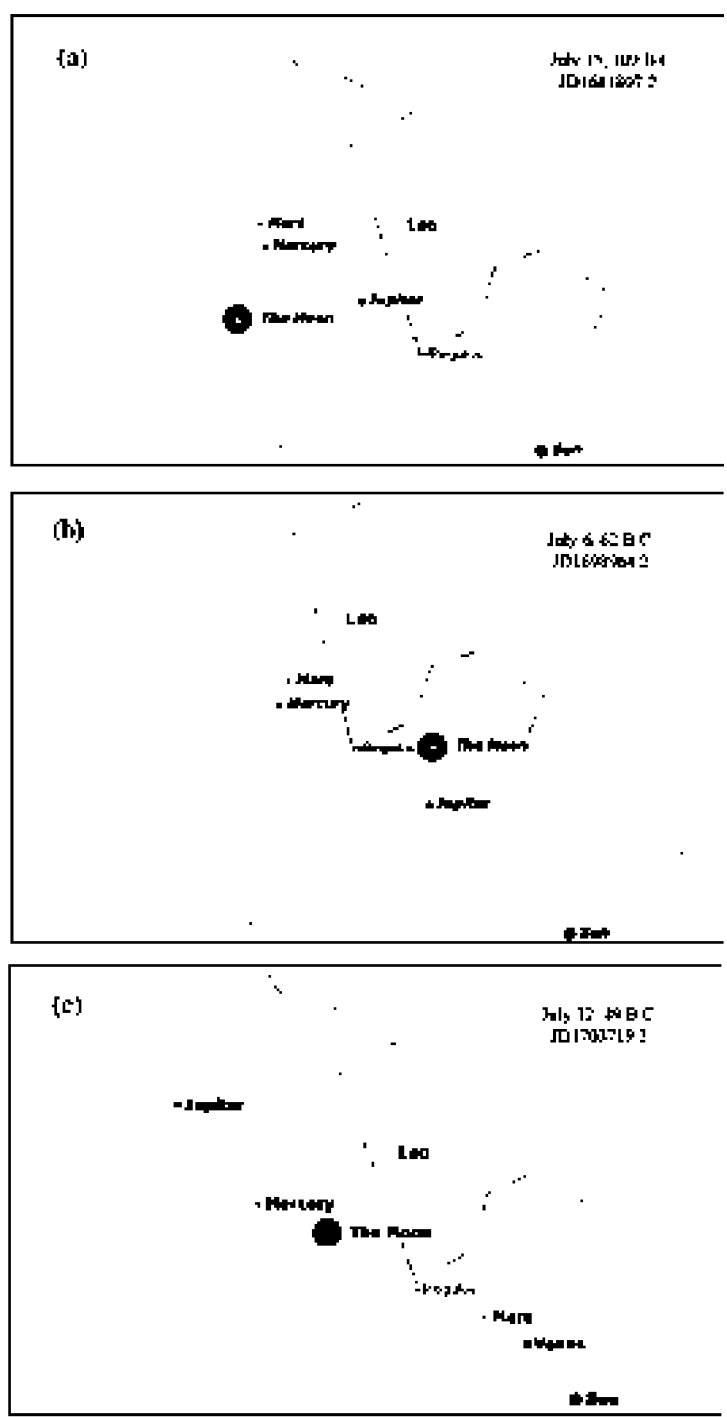

FIG. 5. Three possibilities for the astronomical diagram as represented in the lion slab, corresponding to Leo's setting after sunset for three dates in the Gregorian proleptic calendar: (a) 15 July 109 B.C. (JD1681807.2), accepted by a few scholars; (b) 6 July 62 в.C. (JD1698964.2), in agreement with the date proposed by Neugebauer and Van Hoessen (ref. 9) as the first entry in their book on Greek horoscopes, the date widely accepted by the scientific community so far; and (c) 12 July 49 B.C. (JD1703719.2), the date discussed in this paper. None of the three precisely represents the position and the order of the planets represented in the lion slab, Mars, Mercury, Jupiter and the crescent moon. However, the last one has suggestive connections with the dates yielded by the presumably astronomical orientation of the main architectural elements of the hierothesion in 49 в.c. Indeed, the importance of the constellation Leo is well illustrated as justifying the presence of several lion statues among the monuments of Nemrud Dag. Images adapted from StarryNight Pro Plus 6. 


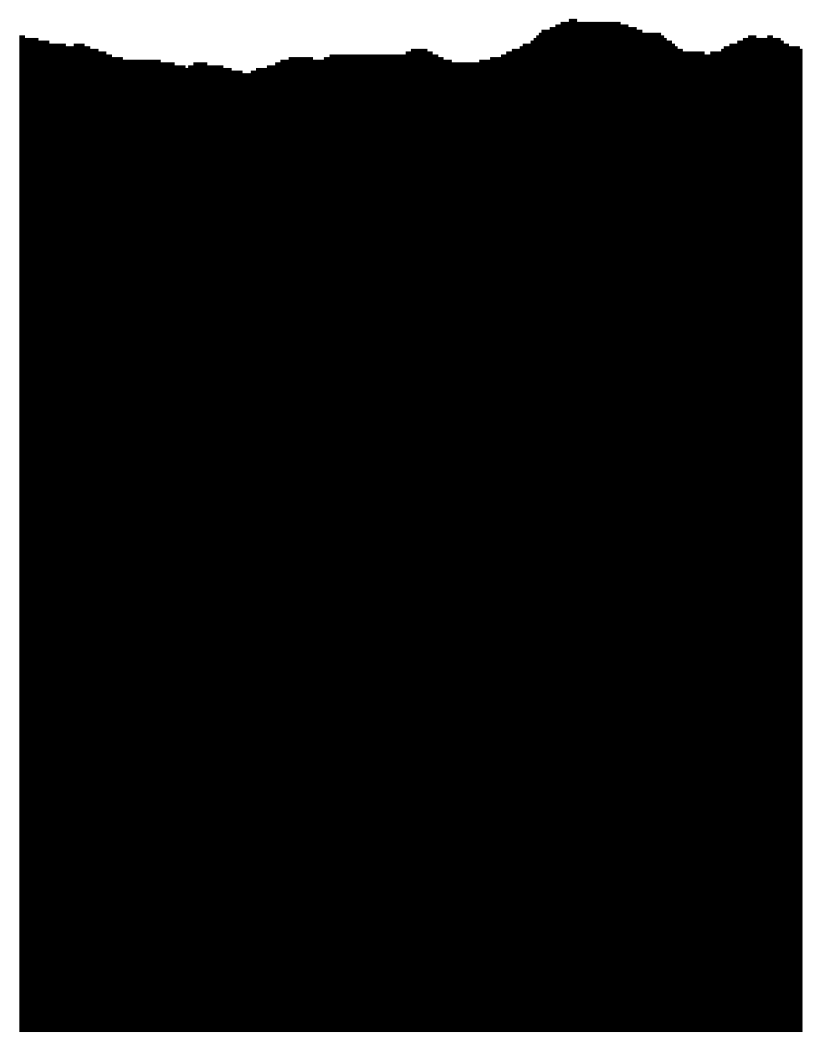

FIG. 6. Sunrise at the summer solstice as observed from the eastern terrace of Antiochos's hierothesion at the summit of Nemrud Dag. The southern socket wall, which is not perpendicular to the basement of the colossal statues (see Fig. 5), is certainly orientated in that direction, permitting a fine-tuned determination of the orientation of other relevant elements of the monument. Photograph courtesy of M. Sanz de Lara.

orientation data. Fatih Cimak is among those who have argued that "these terraces were not built on any axis and the location of each was dictated by the shape of the mountain". ${ }^{12}$ Our initial results indicated that this was not true and that the eastern and western terraces had been constructed on an axis that closely followed the solstitial line linking summer solstice sunrise with winter solstice sunset. Our in situ data (see Figure 3) clearly indicate that this was the case, since both terraces showed solstitial alignments, but with an important nuance. One of the main structures on the site, the huge plinths holding the divine colossi in the eastern terrace, showed a deviation of nearly 6 degrees from the solstitial line. This orientation would signal, within the 
errors, either sunrise on 23 July or 22 May Gregorian (with a margin of a day), or the rising of Regulus during the reign of Antiochos I (extinction and refraction being taken into account). The second possibility was fascinating, considering the possible links between Regulus in Leo and the king. However, it was the possibility of sunrise on 23 July that gave the most interesting and unexpected result.

There is a paucity of information about the calendar that was in use in the Kingdom of Commagene during the reign of Antiochos I. However, considering the epoch, the location of Commagene, and the fact that the land was colonized by the Assyrians with southern Mesopotamian people, ${ }^{13}$ it would be reasonable to support the idea that the Commagenian calendar was based on the Babylonian lunisolar calendar (adapted also by the Seleucid and Parthian dynasties ${ }^{14}$ ), making use of the Macedonian name equivalents of the months in the Greek inscriptions such as the nomos at Antiochos's hierothesion. ${ }^{15}$ Lunar months were usually reckoned from the observation of the first crescent after conjunction. With these simple assumptions in mind, the date of 23 July suddenly converted into Loios 11 (the second day of the feast mentioned in the nomos) in year 49 B.C., the 21st or 22nd reign year of Antiochos (see Figure 2). This result was indeed reinforced if the second festival cited at the nomos was considered. Audnayos 16 in 49 B.C. would have fallen on 23 December. Consequently, the winter solstice sunset-aligned colossi of the western terrace would have been facing sunset on Antiochos's birthday in that particular year, if we bear in mind the slow horizontal movement of the sun close to the solstices (see Figure 7). Hence, the eastern terrace colossi were facing sunrise (and Regulus's rising) on the celebration of Antiochos's ascent to the throne and the western terrace colossi, sunset on the day of Antiochos's birthday, both events in the year 49 в.C.

To our surprise, in the new moon of Loios in the same year, on 12 July (see Figure 5(c)), another planetary conjunction including Jupiter, Mercury, Mars, and indeed the crescent moon, had taken place in the constellation of Leo. So the lion slab may also fit in the series of astronomical events, complementing our results. This date had already been discussed by Neugebauer and Van Hoessen but was discarded in the light of the possibility that the planet Venus might also have been visible under exceptional atmospheric conditions. For us, however, this is a crucial point. We have already stated that the goddess Commagene would stand within the daimones for the local goddess of fertility, a form of Hellenistic Hera or Roman Juno. Most probably this was a form of Anahita in the Iranian interpretation (certainly the dominant in the iconography of Nemrud Dag). In Antiochos's times, in the region, none of these divinities was ever manifested in the moon but rather in the planet Venus. Actually, the moon was considered male and usually identified with the lunar god of Harran. ${ }^{16}$ Consequently, the conjunction of the planet Venus and Regulus in the following days may offer an alternative and suggestive explanation for the dexiosis scene between the king and goddess Commagene. ${ }^{17}$ 


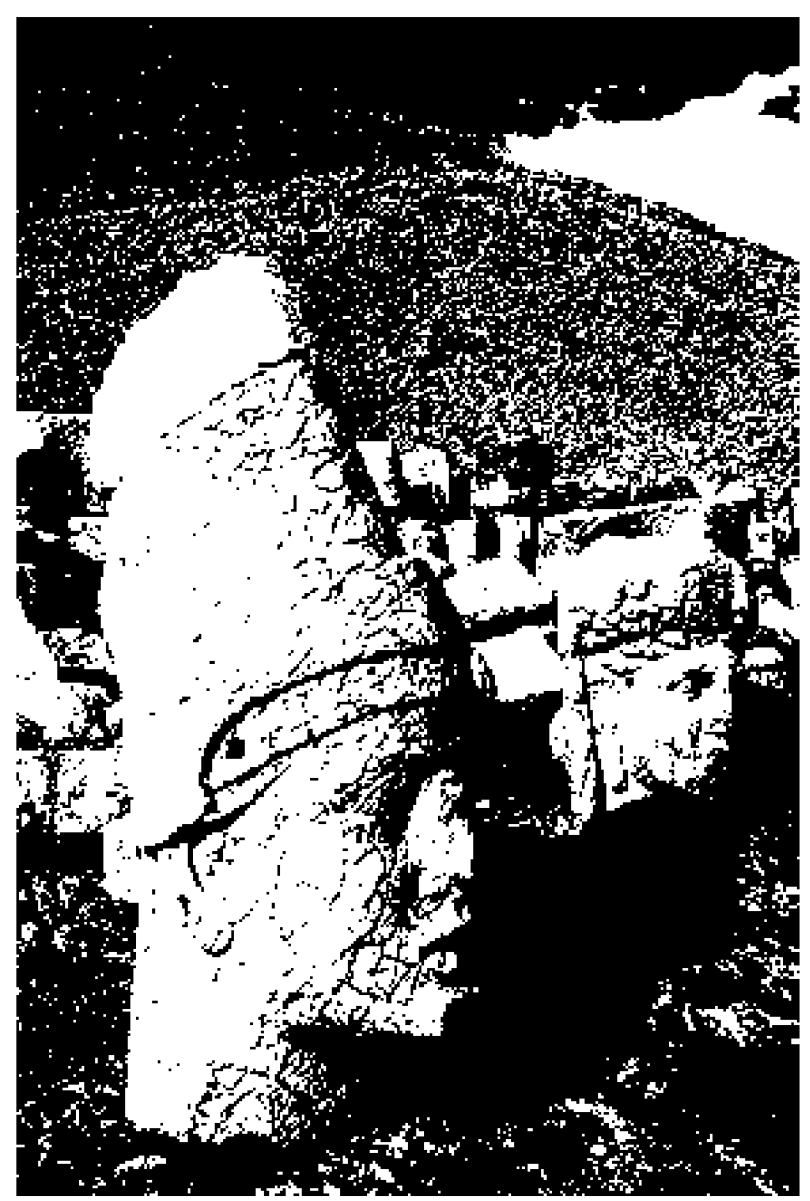

FIG. 7. The western terrace heads of the statues of King Antiochos I and of goddess Commagene were facing, when standing on the corresponding colossi, sunset on Audnayos 16 in 49 в.C., in dates close to the winter solstice of that year (actually the western terrace is orientated in that suggestive astronomical direction). This date (Audnayos 16) corresponded to the birthday of the king and was one of the two important dates commemorated and celebrated at the monument according to the nomos inscription on site. Photograph courtesy of M. Sanz de Lara. Images adapted from StarryNight Pro Plus 6.

\section{Conclusions}

On the one hand, the five cyclopean statues of the eastern terrace would have been facing sunrise followed by the rising (obscured by the solar glare) of their celestial manifestations in the constellation Leo on 23 July 49 B.C. (see Figure 8), commemorating Antiochos's ascent to the throne as explicitly mentioned in the nomos inscription. On the other hand, a few months later, their equivalents of the western terrace would have been facing sunset on 23 December 49 B.c. in commemoration of the king's birthday. ${ }^{18}$ Consequently, according to our new proposal, the main elements of the 


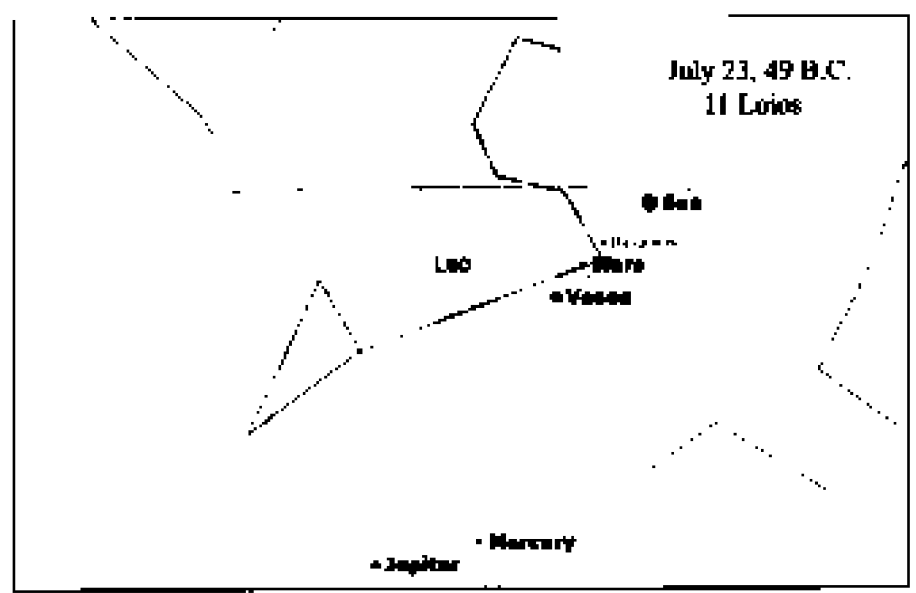

FIG. 8. Sunrise on Loios 11 (23 July) 49 B.C. from the eastern terrace, several days after the new moon. The azimuth of sunrise (and in fact of Regulus's rising) on Loios 11, the second day of the ascent to the throne festival, would be in agreement with the orientation of the colossi of the eastern terrace. On these particular events, the moon is absent from the celestial region of Leo but Jupiter, Mercury and Mars are still within the limits of the constellation. A new planet, Venus is added to the group. According to the hypothesis defended in this paper, the four colossi represented these four planets. In particular, the goddess Commagene would stand for the planet Venus, in agreement with historical and religious considerations, and not for the moon as is frequently considered and accepted without much challenge. See the text for further details. Image adapted from StarryNight Pro Plus 6.

eastern and western terraces of the hierothesion must have been deliberately aligned to sunrise of Loios 11 and sunset of Audnayios 16, respectively, in the year 49 B.C.

Hence, 49 в.C. appears as the most likely date for the beginning of the construction of Antiochos's hierothesion at Nemrud Dag. Besides, apart from the unmistakable astronomical evidence, 49 в.C. has two additional historical advantages over 62 в.C., the commonly accepted date in literature and public outreach. On the one hand, we know that the hierothesion had not been completed when Antiochos I died. Thus, a period of 13 years between the beginning of works on site in 49 в.C. and king's death in 36 B.C. seems much more reasonable that a period of 26 years, as implied by 62 в.C. On the other hand, in 62 B.C., Antiochos I was a young petty king of a tiny country who had just been confirmed on the throne by his Roman overlord Pompey the Great. However, in 49 B.C., the king was in his forties and was acting as a necessary balance between Rome (at the dawn of its civil war between Pompey and Caesar, who crossed the Rubicon that same year) and the powerful Parthians, his Iranian cognates, governed by his son-in-law Orodes II, who had just destroyed Crassus's army at Carrhae a few years earlier (53 B.C.). Antiochos was at the zenith of his power and political influence and could have decided to build the monument his glory deserved. 
During the first century B.C., the land of Commagene was the scene of a celestial drama, encrypted in a new cult and a series of unparalleled monuments, ${ }^{19}$ that we can hopefully try to uncover. Our final conclusion is that Antiochos's hierothesion at Nemrud Dag reflects the situation of the skies at precise dates of the year 49 B.C.: Loios new moon with the third occasion in 60 years of a singular planetary conjunction, Loios 10/11 in commemoration of Antiochos's ascent to the throne, and Audnayos 16 , celebrating the king's birthday. This has been confirmed by local archaeology, the nomos inscription and astronomy, suggesting that the construction of the monument began in this particular year, reflecting the religious tradition of the country and the new cult established by Antiochos.

\section{Acknowledgements}

We wish to express our acknowledgement to Eugene Milone for making accessible some of his unpublished materials and results, to Roger Beck for his supportive comments, and to Margarita Sanz de Lara for her excellent images. This work is partially financed under the framework of the projects P310793 "Arqueoastronomía" of the IAC, and AYA2007-60213 "Orientatio ad Sidera II" of the Spanish MICINN.

\section{REFERENCES}

1. R. D. Sullivan, "The dynasty of Commagene", Aufstieg und Niedergang der römischen Welt, ed. by H. Temporini and W. Haase, ii (Berlin, 1977), 732-98.

2. M. Boyce, "In Commagene, Syria and Egypt", A history of Zoroastrianism, iii (Leiden, 1991), chap. 10, pp. 309-60.

3. J. D. Hawkins, "Scripts and texts", The Luwians, ed. by H. Graig Melchert (Leiden, 2003), 129-69.

4. T. Bryce, "Kummuh", The Routledge handbook of the peoples and places of ancient Western Asia (London, 2009), 397-8.

5. D. H. Sanders (ed.), The Hierothesion of Antiochus I of Commagene: Results of the American excavations directed by Theresa B. Goell, i: Text; ii: Illustrations (Winona Lake, 1996).

6. Translated by S. M. Burstein, in F. Cimak, Commagene, Nemrut (Istanbul, 1995), 17-18.

7. Boyce, op. cit. (ref. 2), 309.

8. Y. Bonnefoy, Diccionario de las mitologías y de las religiones de las sociedades tradicionales del mundo antiguo, i (Barcelona, 1996), 286-7 and 373-4.

9. O. Neugebauer and H. B. Van Hoessen, Greek horoscopes (Memoirs of the American Philosophical Society, xlviii; Philadelphia, 1959), 14-16.

10. E. F. Milone and B. Desnoyers Winmill, "Possible astronomical alignments and the interpretation of the hierothesion at Nemrud Dagh", private communication. Also relevant is D. H. Kelley and E. F. Milone, Exploring ancient skies: An encyclopedic survey of archaeoastronomy (New York, 2003), chap. 15.

11. V. S. Tuman, "The tomb of Antiochos revisited: Planetary alignments and the deification of the king", Archaeoastronomy (USA), vii (1984), 56-69.

12. Cimak, Commagene, Nemrut (ref. 6).

13. Bryce, op. cit. (ref. 4), 397.

14. E. J. Bickerman, "Notes on Seleucid and Parthian chronology", Berytus archaeological studies, no. 1943 (2008), http://ddc.aub.edu.lb/projects/archaeology/berytus-back/berytus08/73.html.

15. R. Hannah, Greek and Roman calendars (London, 2005), 95. 
16. Bonnefoy, op. cit. (ref. 8), 286 and 373.

17. However, it is worth noting that, as Roger Beck has suggested, "the identification of the person of 'my fatherland all-nurturing Commagene' with Venus rather than, as traditionally, with the Moon, poses an unnecessary choice. Why not both, just as 'Apollo-Mithras-Helios-Hermes' refers to both Mercury and the Sun?" Hence, given the Hellenistic influence where the moon is female, Commagene might stand for both celestial bodies, Venus and the moon.

18. The sky configuration of that particular day may additionally explain the presence of the second totemic animal present in the plinths together with the lion and the statues of the divinities, the eagle (also ubiquitous at the Mount Nemrud ruins), provided the constellation Aquila and its brightest star Altair were dominating the western horizon at dusk, as an alternative manifestation of the power of the king.

19. His son Mithradates II (or perhaps Antiochos himself) built a much smaller hierothesion for her mother Isias at Karakush (see Fig. 1). Certain elements of this smaller but still magnificent monument have suggested an astronomical interpretation: see R. Beck, "The astronomical design of Karakush, a royal burial site in ancient Commagene: An hypothesis", Culture and cosmos, iii (1998), 10-31. 
